\title{
Fidelino de Figueiredo na origem dos estudos de Literatura Portuguesa no Brasil
}

\section{ANTONIO SOARES AMORA}

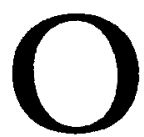

$s$ idealizadores da Universidade de São Paulo - estávamos então no começo dos anos 30 - partiram do princípio que, para fundar uma instituição de ensino superior que contribuísse, efetivamente, para a renovaçăo da cultura brasileira, era indispensável criar, na sua base, uma faculdade voltada ao mesmo tempo para a docência e a pesquisa ou, mais explicitamente, para a formaçáo de jovens orientados para a produçáo original no campo da filosofia, das ciências ou das letras e para, com o espírito de pesquisa ou especulativo, atuar no ensino. E esta é a razáo porque, para os quadros docentes dessa faculdade, que veio a denominar-se Filosofia, Ciências e Letras, foram convidados, no Brasil e no estrangeiro, de preferência especialistas que se vinham distinguindo por suas contribuiçōes para o progresso do conhecimento e se mostravam interessados na formaçáo de discípulos. Correspondendo a esse modelo, foram contratados em Portugal, para a pesquisa e o ensino nas áreas da língua e da literatura portuguesa, dois professores, Rebelo Gonçalves, jovem professor da Faculdade de Letras de Lisboa, que começava a impor-se como brilhante filólogo e Fidelino de Figueiredo, já com renome internacional, pelo seu trabalho na renovação da crítica, da história e da teoria literária em Portugal e pela ação que desenvolvera na criaçáo dos estudos de literatura portuguesa na Espanha (Universidade Central de Madri) e nos Estados Unidos (Universidade da Califórnia, em Berkeley).

Contratado, em 1938 (1), para ministrar um curso de literatura luso-brasileira, Fidelino de Figueiredo, táo logo iniciou suas atividades de ensino e pesquisa, solicitou a Universidade três medidas que considerava essenciais ao desempenho do programa de ação que se impôs: a primeira, a instalaçáo de um gabinete de trabalho, indispensável ao exercício de seu tempo integral na instituição; a segunda, a efetivação do desdobramento da cadeira em dois cursos: Literatura Portuguesa (que 
era sua especialidade e, portanto, ficaria a seu cargo) e Literatura Brasileira, que, a seu ver, deveria, por todas as razóes, ficar sob a responsabilidade de um professor nacional (2); e como terceira medida, a criação de uma linha de publicação destinada a recolher a produçáo crítica da cadeira e a promover suas relaçóes com congênere produçáo nacional ou estrangeira. $O$ gabinete de trabalho em que Fidelino de Figueiredo começou a escrever sua produçáo paulista e onde, de 1938 a 1939, era normalmente encontrado, criou na cadeira de Literatura Portuguesa da USP a tradição do ensino e da pesquisa em efetivo tempo integral na Faculdade. Quanto às publicaçóes da cadeira, recorde-se que já em fins de 1938 Fidelino de Figueiredo publicaria num boletim da Faculdade, intitulado Letras $n^{0} 1$, os resultados de suas últimas pesquisas de documentos sobre a ambiência heróica em Portugal, no século XVI (3). E a separação dos cursos das literaturas de língua portuguesa, em que sempre insistiu, acabou por se fazer em 1940. Apesar de extremamente dedicado às aulas, ao convívio universitário, às suas pesquisas, à sua a no campo da teoria literária e ao intenso relacionamento epistolar com o mundo (4), Fidelino de Figueiredo ainda participou do programa de difusão cultural para que também estava voltada a Universidade de São Paulo e, neste sentido, deu regular colaboraçáo à imprensa (5). Em 1939, para atender ao interesse de grande audiência de profissionais do ensino, da crítica e da biblioteconomia, deu, na Biblioteca Pública Municipal de São Paulo, quatro conferências sobre as últimas tendências da bibliografia, da historiografia e da crítica literárias, logo editadas num volume, Aristarchos, de sabida influência na crítica brasileira e portuguesa, bem como no ensino da literatura, que então começava a expandir-se no Brasil, no curso superior, ou de Letras.

Tendo colaborado também na fundaçáo da Universidade do Brasil, no Rio de Janeiro, onde organizou, em 1940 e 1941, o curso de Literatura Portuguesa da Faculdade Nacional de Filosofia, hoje Faculdade de Letras da UFRJ, Fidelino de Figueiredo retomou, em 1942, suas atividades na USP e, em um decênio, completou o projeto do curso iniciado em 1938:

- fez publicar mais oito boletins de Letras, sendo três de sua autoria e dois com seu prefácio;

- formou um corpo de assistentes e continuadores, levando dois ao doutoramento e, destes, um à livre docência;

- a partir de 1946 deu ao seu curso dois níveis, um de licenciatura e outro de especialização (mais tarde transformado em pós-graduação); 
- convencido de que uma cadeira tinha limitados recursos de pesquisa e ensino, propôs à Faculdade de Filosofia, Ciências e Letras, em 1948, a criação de um Instituto de Literatura, de pronto aprovado, mas por dificuldades materiais só instalado, com algumas modificaçóes, em 1955, como Instituto de Estudos dos Portugueses da USP (hoje Centro de Estudos Portugueses), instituiçáo que inspirou a criação de vários centros semelhantes no país;

- participando, mais uma vez, do programa de difusáo cultural da Universidade de São Paulo deu, em 1942, na Biblioteca Pública Mu-

Fidelino Figueiredo

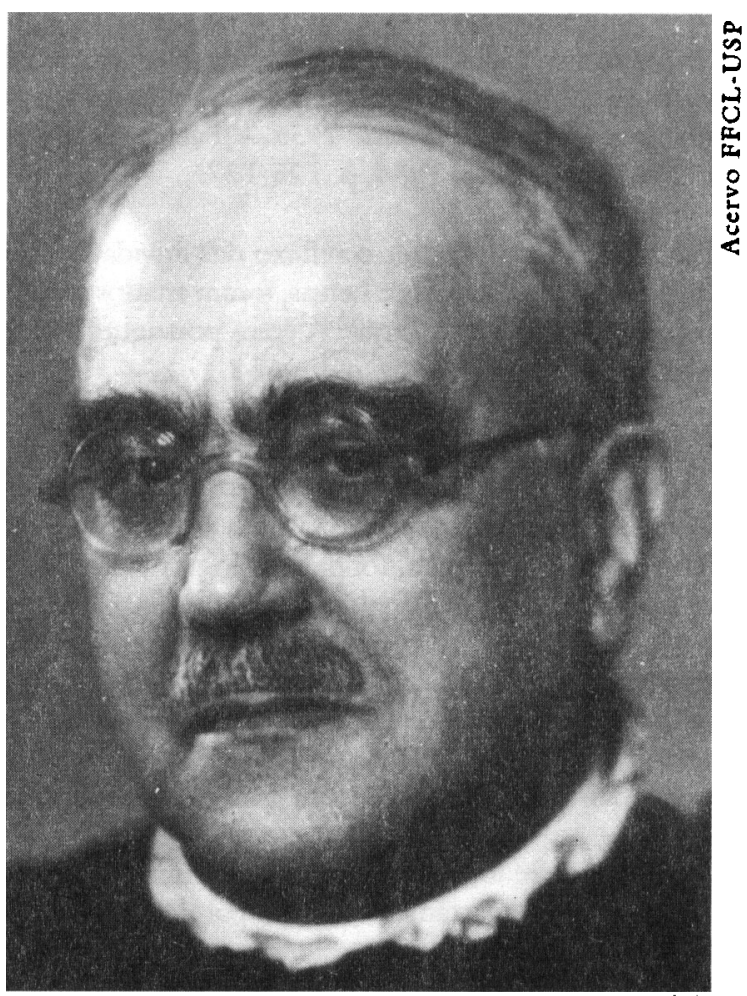

nicipal de São Paulo e novamente para um grande público, em quatro conferências destinadas a comemorar o centenário do nascimento de Antero de Quental, uma demonstraçáo de como entendia e ensinava a crítica: náo como biografia ou impressóes pessoais de leituras, mas como uma "direção de espírito" (6).

E sempre convencido da importância das idéias, manteve, até 1947, sua colaboração jornalística no Brasil.

Em dezembro de 1951, ao viajar para Portugal por motivo de 
doença que the veio ser fatal em 1967, Fidelino de Figueiredo podia estar certo de que, em São Paulo, deixara um centro de estudos de literatura portuguesa, orientado e potencializado para uma fecunda produçáo, para sua disseminação no Brasil e para um amplo relacionamento internacional. Estava cumprida sua missão no Brasil.

\section{Notas}

1 Rebelo Gonçalves, que lecionou na USP de 1935 ao fim de 1937, teve importante papel na contrataçăo de Fidelino de Figueiredo. Vejam-se a propósito suas cartas a Fidelino de Figueiredo, escritas de 1935 a 1937, hoje na correspondência passiva de Fidelino de Figueiredo (v. nota 4)

2 O desdobramento da cadeira de literatura luso-brasileira em duas disciplinas autônomas foi proposto em 1936 e embora logo aprovado pela congregação da Faculdade, sé veio a efetivar-se em 1940. V. Anudrio 1936 - Faculdade de Filosofia, Ciências e Letras, Universidade de São Paulo, 1936, p. 125-127.

3 Os Boletins, concebidos para ser o reflexo das atividades científicas de cada cadeira da Faculdade de Filosofia, Ciências e Letras, foram criados em 1936. Fidelino de Figueiredo iniciou a série dos bolerins de Letras: A épica portuguesa no século XVI. Com apêndices documentares. Săo Paulo, Letras, no1, 1938.

4 Uma simples leitura do catálogo da correspondência passiva de Fidelino de Figueiredo dá idéia de suas relaçōes literárias. O acervo dessa correspondência (perto de 11.500 cartas, bilhetes e telegramas) está no Centro de Estudos Portugueses da USP e seu catálogo, feito por Herti Ferreira, foi publicado por Julio Garća Morejón em Dos colectionadores de angustia. Assis-SP, Faculdade de Filosofia, Ciências e Letras, 1967, p. 77-111.

5 Toda a colaboraçáo jornalística de Fidelino de Figueiredo está colecionada em sua biblioteca, doada à Faculdade de Ietras da Universidade de Lisboa. Pequena parte dessa colaboração foi republicada pelo Autor em alguns de seus livros, como Últimas apenturas c cultura interpalar. O restante, que tem grande interesse, aguarda republicaçăo.

6 V. Fidelino de Figueiredo, Aristarcho. Quatro conferências sobre metodologia da crítica literária. São Paulo, Departamento Municipal de Cultura, Coleção do D.C., v. XXIII, 1939.

António Soares Amora é Professor Emérito da USP. 